Open Access

\title{
The dual PI3K/mTOR inhibitor NVP-BEZ235 inhibits proliferation and induces apoptosis of burkitt lymphoma cells
}

\author{
Chuntuan Li, Pengliang Xin, Huifang Xiao, Yan Zheng, Yuanling Huang and Xiongpeng Zhu*
}

\begin{abstract}
Background: Phosphatidylinositol 3-kinase/Akt/mammalian target of rapamycin (PI3K/Akt/mTOR) pathway is a therapy target of cancer. We aimed to confirm the effect of dual PI3K/mTOR inhibitor NVP-BEZ235 on cell proliferation and apoptosis in Burkitt lymphoma (BL) cells.

Methods: Two human BL cell lines, CA46 and RAJl were used in this study. The proliferation of BL cells was detected by manganese tricarbonyl transfer (MTT) assay. Cell cycle and apoptosis assay were examined by flow cytometric analysis. The phosphorylation levels of AKT (Thr308), AKT (Ser473), and RPS6 were evaluated by western blot analysis.

Results: NVP-BEZ235 significantly inhibited the proliferation of BL cells (CA46 and RAJI) and the inhibition effect was time and dose-dependent. Cell cycle analysis indicated that the cells (CA46 and RAJI) were mostly arrested in G1/G0 phase. Cell apoptosis assay showed that the late apoptotic cells were significantly increased after $72 \mathrm{~h}$ treatment by $100 \mathrm{nmol} / \mathrm{L}$ of NVP-BEZ235. In addition, results also found that NVP-BEZ235 reduced the phosphorylation levels of AKT (Thr308), AKT (Ser473), and PRS6 in BL cells (CA46 and RAJI). Moreover, this inhibition effect on phosphorylation was dose-dependent.
\end{abstract}

Conclusions: NVP-BEZ235 effectively inhibited cell proliferation by G0/G1 cell-cycle arrest and induced apoptosis through deregulating PI3K/Akt/mTOR pathway in BL cells.

Keywords: Burkitt lymphoma, Phosphatidylinositol 3-kinase/Akt/mammalian target of rapamycin pathway, NVP-BEZ235, Cell proliferation, Apoptosis

\section{Background}

Burkitt lymphoma (BL), as a highly aggressive nonHodgkin lymphoma, drives from germinal center (GC) B cells $[1,2]$. There are three recognized clinical variants based on the WHO classification: endemic (eBL, found predominantly in equatorial Africa), sporadic (sBL, the predominant type found in non-malarial areas), and associated with immunodeficiency (including human immunodeficiency virus-associated and post-transplantation lymphoproliferative disorder after solid organ transplantation) $[1,3,4]$. Based on recent reports and statistics, BL is the most common form of non-Hodgkin lymphoma in

\footnotetext{
*Correspondence: xiongpengzhu@163.com
Department of Haematology, First Hospital of Quanzhou Affiliated to Fujian
Medical University, 248 East Street, Licheng District, Quanzhou 362000, Fujian

* Correspondence: xiongpengzhu@163.com
Department of Haematology, First Hospital of Quanzhou Affiliated to Fujian
Medical University, 248 East Street, Licheng District, Quanzhou 362000, Fujian

* Correspondence: xiongpengzhu@163.com
Department of Haematology, First Hospital of Quanzhou Affiliated to Fujian
Medical University, 248 East Street, Licheng District, Quanzhou 362000, Fujian Province, China
}

children $[5,6]$ and the incidence is higher in males than in females [7-9]. Currently, chemotherapy remains the main treatment modality for BL. However, the acquired chemoresistance remains a challenging issue and reduces the possibility of effective salvage and cure [10]. Meanwhile, the clinical outcome is still poor in patients with over 40 years old $[2,11]$. Therefore, a novel and effective treatments are needed to enhance the efficacy of chemotherapy and improve clinical outcomes in the treatment of $\mathrm{BL}$ patients.

The phosphatidylinositol 3-kinase/Akt/mammalian target of rapamycin (PI3K/Akt/mTOR) pathway deregulation is a common event in human cancer and associated with the tumor cell proliferation, growth and apoptosis [12, 13]. Currently, this pathway has become a favorable therapy target of cancer [13-15], including BL $[16,17]$. 
However, there is still no feasible and effective drug targeting this pathway in the clinical treatment of $\mathrm{BL}$. Meanwhile, it has been reported that the deregulation of PI3K/Akt/mTOR pathway can leading to chemoresistance in BL [18]. Thus, it is important to find a novel drug targeting PI3K/Akt/mTOR pathway for treating BL.

NVP-BEZ235 is a dual inhibitor of PI3K and mTOR. It is a synthetic compound belonging to the class of imidazoquinolines, and inhibits PI3K and mTOR catalytic activity by competitively binding to the ATP-binding cleft [19]. Previous studies have reported its inhibition in tumor cell proliferation and growth as well as promotion in apoptosis in many other cancers [20-22]. Meanwhile, Shortt et al. [23] reported that NVP-BEZ235 induced apoptosis of BL cells was associated with the PI3K/Akt/ mTOR pathway in MYC-driven BL cells. However, it is unknown that whether this effect of NVP-BEZ235 still exist in BL cells without MYC-driven. Moreover, Shortt et al. [23] also showed that the BEZ235-induced apoptosis occurred independently of p53. Thus, we have performed this study using two BL cell lines (CA46 and RAJI, which all have mutant p53) to further assess and confirm the effects of NVP-BEZ235 on BL cells.

\section{Materials and methods}

\section{Cell lines and reagents}

Two human BL cell lines, CA46 and RAJI, were purchased from KeyGEN Biotech (NanJing, China), and cultured in RPMI 1640 medium which contained $10 \%$ newborn calf serum (Gibco, Waltham, MA, USA) in a humidified $37{ }^{\circ} \mathrm{C}$ incubator with $5 \% \mathrm{CO}_{2}$.

NVP-BEZ235 was purchased from Selleckchem (Houston, TX, USA) and dissolved in dimethylsulfoxide (DMSO) to a concentration of $10 \mathrm{mmol} / \mathrm{L}$. Before experiment, NVP-BEZ235 was stored at $-20{ }^{\circ} \mathrm{C}$. In the following experiments, it would be further diluted to an appropriate final concentration.

\section{Cell proliferation assay}

Cells from two cell lines (CA46 and RAJI) were respectively seeded in different 96 -well plates with $10 \%$ newborn calf serum at a density of $1 \times 10^{4}$ cells/well. The cells were respectively treated with NVP-BEZ235 at different concentrations $(1,10,50,100,500$ and $1000 \mathrm{nmol} / \mathrm{L})$ for 24 , 48 , and $72 \mathrm{~h}$. Meanwhile, the cells incubated with equal volume of DMSO instead of NVP-BEZ235 were used as control. After incubation period, 3-(4, 5-dimethylthiazolyl2)-2, 5-diphenyltetrazolium bromide (MTT, Amresco, $\mathrm{OH}$, USA) was immediately added to the wells at a final concentration of $20 \mu \mathrm{mol} / \mathrm{L}$ and the cells were incubated for $4 \mathrm{~h}$. Subsequently, the cells were collected through centrifugation. The supernatant was discarded and $150 \mu \mathrm{l}$ DMSO was used to suspend the cells in each well. Finally, measurement of absorbance at $490 \mathrm{~nm}$ was performed using an automatic multi-well spectrophotometer (Bio-Tek Instruments, Vermont, USA). The inhibition rate was calculated based on the formula: Inhibition rate $(\%)=(1-$ Absorbance of wells treated with NVPBEZ235 /Absorbance of control) $\times 100$.

\section{Cell cycle analysis}

Cells from two cell lines were respectively seeded in different 6-well plates with $10 \%$ newborn calf serum at a density of $1 \times 10^{5}$ cells $/ \mathrm{ml}$. The cells were respectively treated with NVP-BEZ235 at concentrations of 10 and $100 \mathrm{nmol} / \mathrm{L}$ for $48 \mathrm{~h}$. Meanwhile, the cells incubated with equal volume of DMSO instead of NVP-BEZ235 were used as control. After incubation period, cells were harvested through centrifugation and washed twice with ice-cold phosphate-buffered saline (PBS). Afterwards, the cells were fixed using $1 \mathrm{ml}$ ice-cold PBS and $3 \mathrm{ml}$ ethanol at $-20{ }^{\circ} \mathrm{C}$ overnight. After fixation, the cells were washed twice with ice-cold PBS again, and then incubated with $30 \mu \mathrm{g} / \mathrm{ml}$ of propidium iodide (PI, Sigma-Aldrich, St Louis, MO) and $40 \mu \mathrm{g} / \mathrm{ml}$ of Rnase (Sigma-Aldrich, St Louis, MO) for $30 \mathrm{~min}$ at room temperature in a dark room. Before analysis by the FACSCalibur cytometer (BD Biosciences, San Jose, CA), the cells were separated through a 200-mesh nylon filter. Data were analyzed using the Modfit LT software (BD Biosciences, San Jose, CA).

\section{Cell apoptosis assay}

BL cells were seeded in 6-well plates with $10 \%$ newborn calf serum at a density of $1 \times 10^{5}$ cells $/ \mathrm{ml}$. The cells were respectively treated with $100 \mathrm{nmol} / \mathrm{L}$ of NVP-BEZ235 for $48 \mathrm{~h}$ and $72 \mathrm{~h}$. Meanwhile, the cells incubated with equal volume of DMSO instead of NVP-BEZ235 were used as control. After treatment, cells were washed twice with ice-cold PBS. Subsequently, apoptosis was assayed using the FITC Annexin V Apoptosis Detection Kit I (BD Biosciences, San Jose, CA, USA), following the manufacturer's instructions. The cells were assessed using flow cytometric analysis. Viable cells were FITC Annexin V and PI -negative cells; cells that were FITCAnnexin V-positive and PI-negative were considered as being in early apoptosis; whereas necrotic cells were FITC-annexin-V negative/low-PI positive; cells that were both FITC-Annexin V-and PI-positive were considered as being in late apoptosis;

\section{Western blot analysis}

In the PI3K/Akt/mTOR pathway, AKT is the central key component of this pathway and activated through phosphorylation at Ser473 and Thr308. Moreover, ribosomal protein S6 (RPS6) would be phosphorylated in the downstream of mTOR signaling [13]. Thus, we 
detected the phosphorylation levels of these proteins through western blot analysis to assess if NVPBEZ235 could affect the PI3K/Akt/mTOR pathway in BL cells.

BL cells were seeded in 6-well plates with $10 \%$ newborn calf serum at a density of $1 \times 10^{6}$ cells $/ \mathrm{ml}$. Meanwhile, the cells were respectively treated with different concentrations of NVP-BEZ235 $(1,10,100$, and $200 \mathrm{nmol} / \mathrm{L})$ for 0 , $3,6,12,24$, and $48 \mathrm{~h}$. The cells incubated with equal volume of DMSO instead of NVP-BEZ235 were used as control. Western blotting was performed as described previously [24]. Briefly, after washing twice by PBS, cells were lysed with RIPA (Radio Immunoprecipitation Assay) lysis buffer (Solarbio, Beijing, China), which contained $1 \mathrm{mmol} / \mathrm{L}$ PMSF (Phenylmethanesulfonyl fluoride). The protein concentrations of the cell lysates were determined using the Enhanced BCA Protein Assay kit (Beyotime, Haimen, China). Proteins were separated by sodium dodecyl sulfate-polyacrylamide (SDS) gel electrophoresis and then transferred to nylon membranes. The membranes were blocked in TBS-T buffer solution containing $5 \%$ non-fat dry milk at $4{ }^{\circ} \mathrm{C}$ overnight. Immunoblotting was performed using rabbit polyclonal antibodies against AKT (1:100 dilution), phosphorylated Akt (Ser473 or Thr308, both 1:100 dilution), RPS6 (1:100 dilution), phosphorylated RPS6 (1:100 dilution), and $\beta$-actin (1:1000 dilution), respectively. Blots were probed with horseradish peroxidase-conjugated secondary antibody (anti-rabbit) and developed using enhanced chemiluminescence reagent (Amersham Biosciences, Piscataway, NJ). All antibodies were purchased from Bioss (BeiJing, China). Band density was imaged and the levels of protein expression quantified using Molecular Imager VersaDoc MP 4000 system (Bio-Rad) and normalized to the $\beta$ actin levels. The phosphorylation levels of proteins were assessed based on the ratios of phosphorylated proteins to the corresponding total proteins.

\section{Statistical analysis}

The data were presented as means $\pm \mathrm{SD}$. Comparison between groups were performed using a Non-parametric test or one-way ANOVA. A value of $\mathrm{P}<0.05$ was considered statistically significant. Statistical analyses were performed using SPSS 17.0 software (Chicago, USA).

\section{Results}

\section{NVP-BEZ235 inhibited BL cell proliferation}

As shown in Fig. 1, the inhibition rates of two BL cell lines were significantly increased with the increasing incubation time and concentration of NVP-BEZ235 $(\mathrm{P}<0.05)$, indicating that NVP-BEZ235 could inhibit the proliferation of BL cells and this antiproliferative effect was time and dose-dependent.

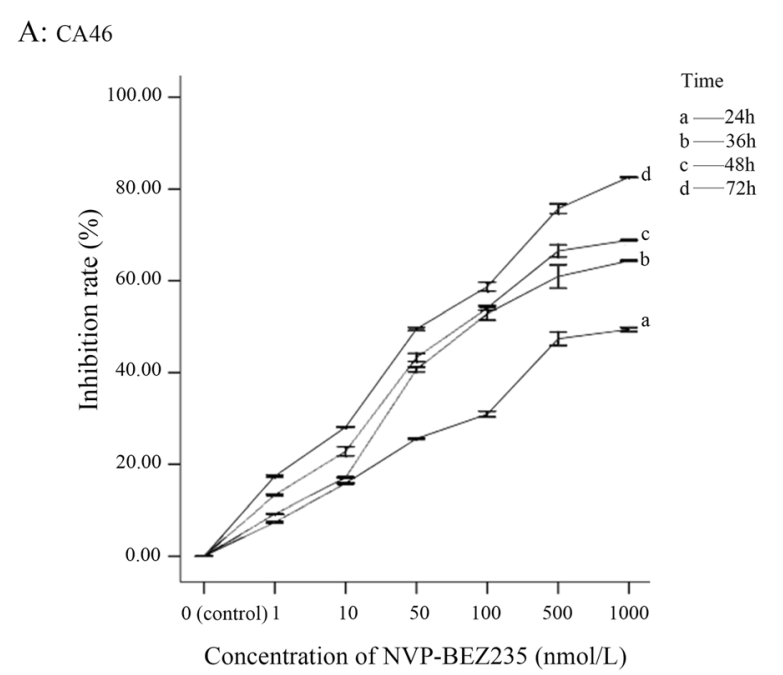

B: RAJI

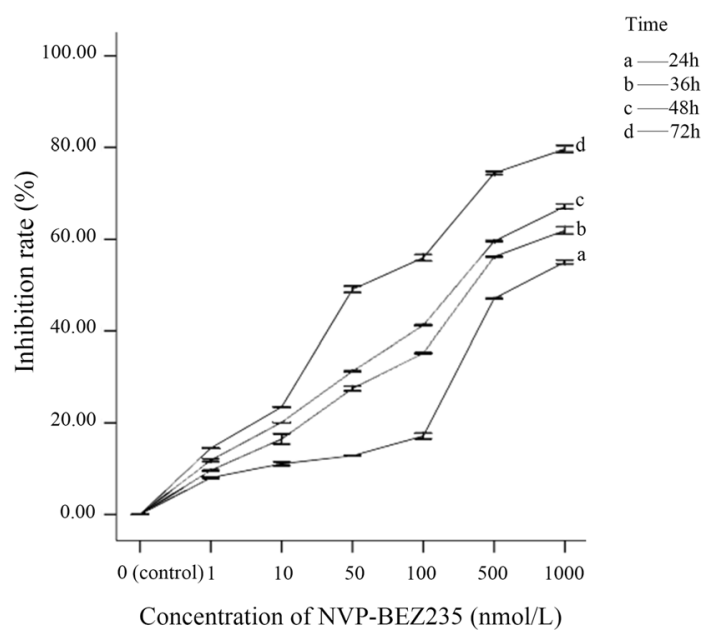

Fig. 1 NVP-BEZ235 inhibited the proliferation of Burkitt lymphoma cells. a CA46; b RAJl

\section{G0/G1 phase arrest induced by NVP-BEZ235}

NVP-BEZ235 induced cell cycle arrest in G1/G0 phase in both BL cell lines (Figs. 2 and 3). Compared with control, cells in the G1/G0 phase were significantly increased $(P<0.05)$ and in $G 2 / M$ and $S$ phases were significantly reduced after $48 \mathrm{~h}$ treatment by $10 \mathrm{nmol} / \mathrm{L}$ or $100 \mathrm{nmol} / \mathrm{L}$ of NVP-BEZ235 $(\mathrm{P}<0.05)$. Moreover, compared with cells treated with $10 \mathrm{nmol} / \mathrm{L}$ NVPBEZ235, there were significantly more cells in G1/G0 phase when cells were treated with $100 \mathrm{nmol} / \mathrm{L}$ NVPBEZ235 $(\mathrm{P}<0.05)$.

\section{Effect of NVP-BEZ235 on cell Apoptosis}

Compared with control, the viable cells (FITC Annexin $\mathrm{V}$ and PI negative) were significantly reduced and the early apoptotic cells (FITC-Annexin V-positive and PI-negative) were significantly increased by the treatment of $100 \mathrm{nmol} /$ 

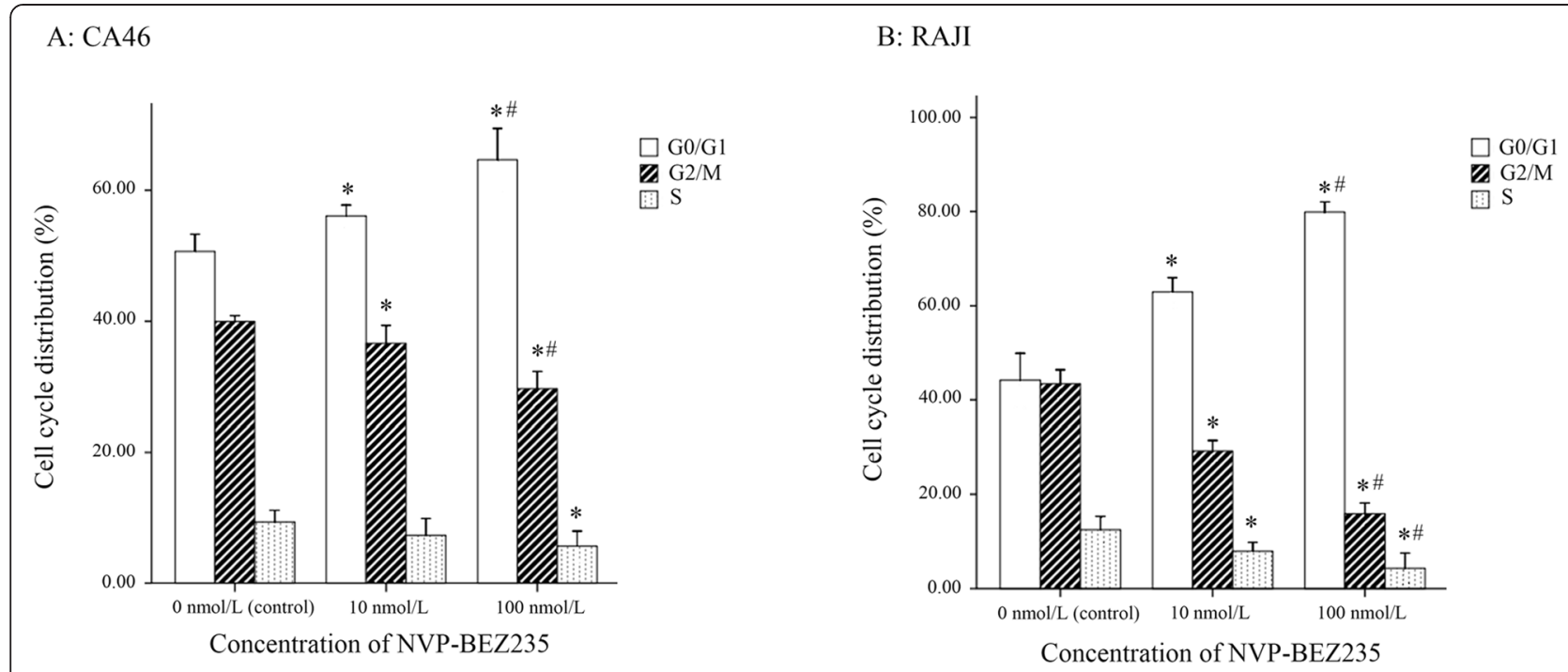

Fig. 2 NVP-BEZ235 blocked the cell cycle of Burkitt lymphoma cells at the G1/G0 phase. a CA46; b RAJI. ${ }^{*} P<0.05$, compared with control; $\# P<0.05$, compared with the cells treated with $10 \mathrm{nmol} / \mathrm{L}$ NVP-BEZ235

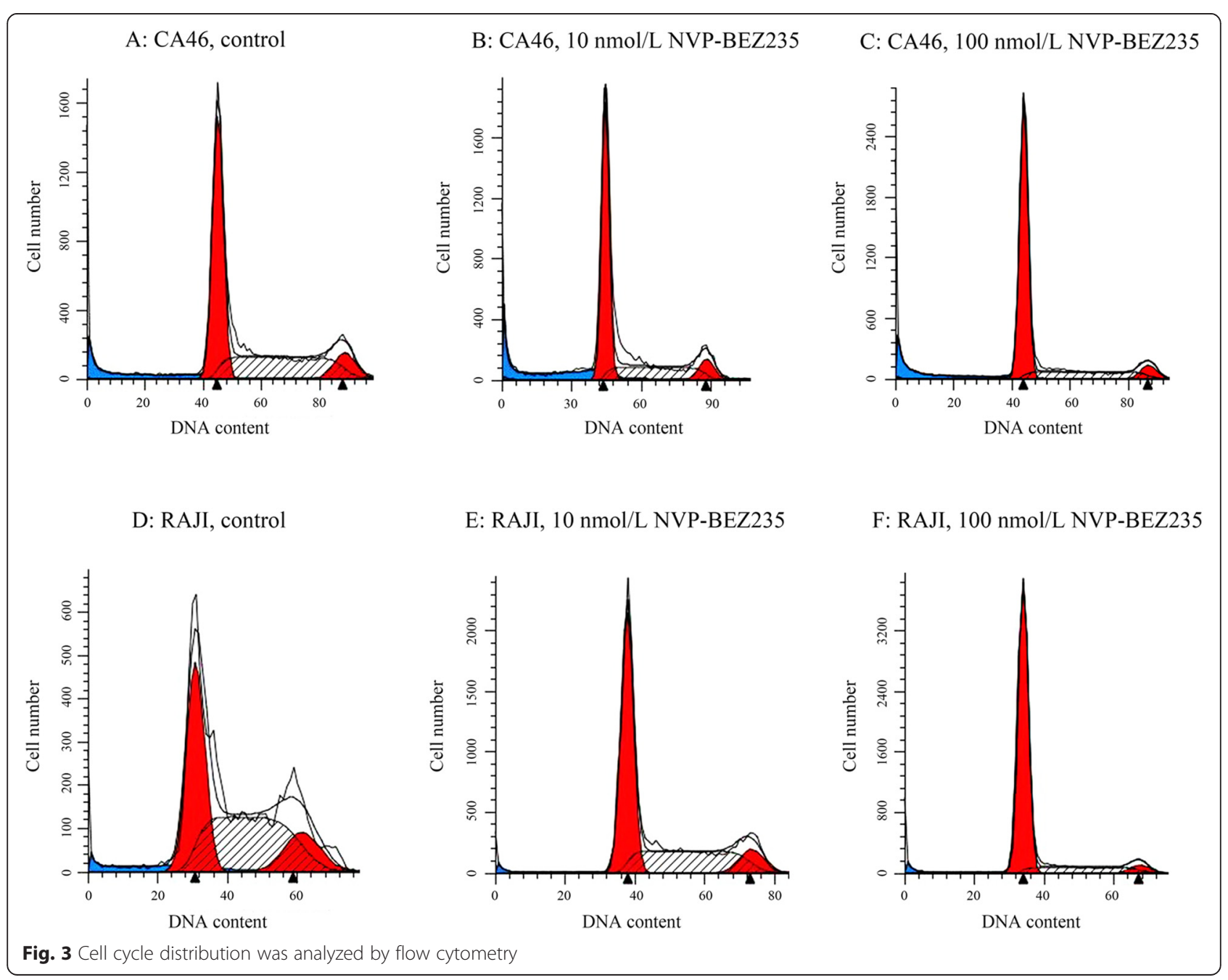



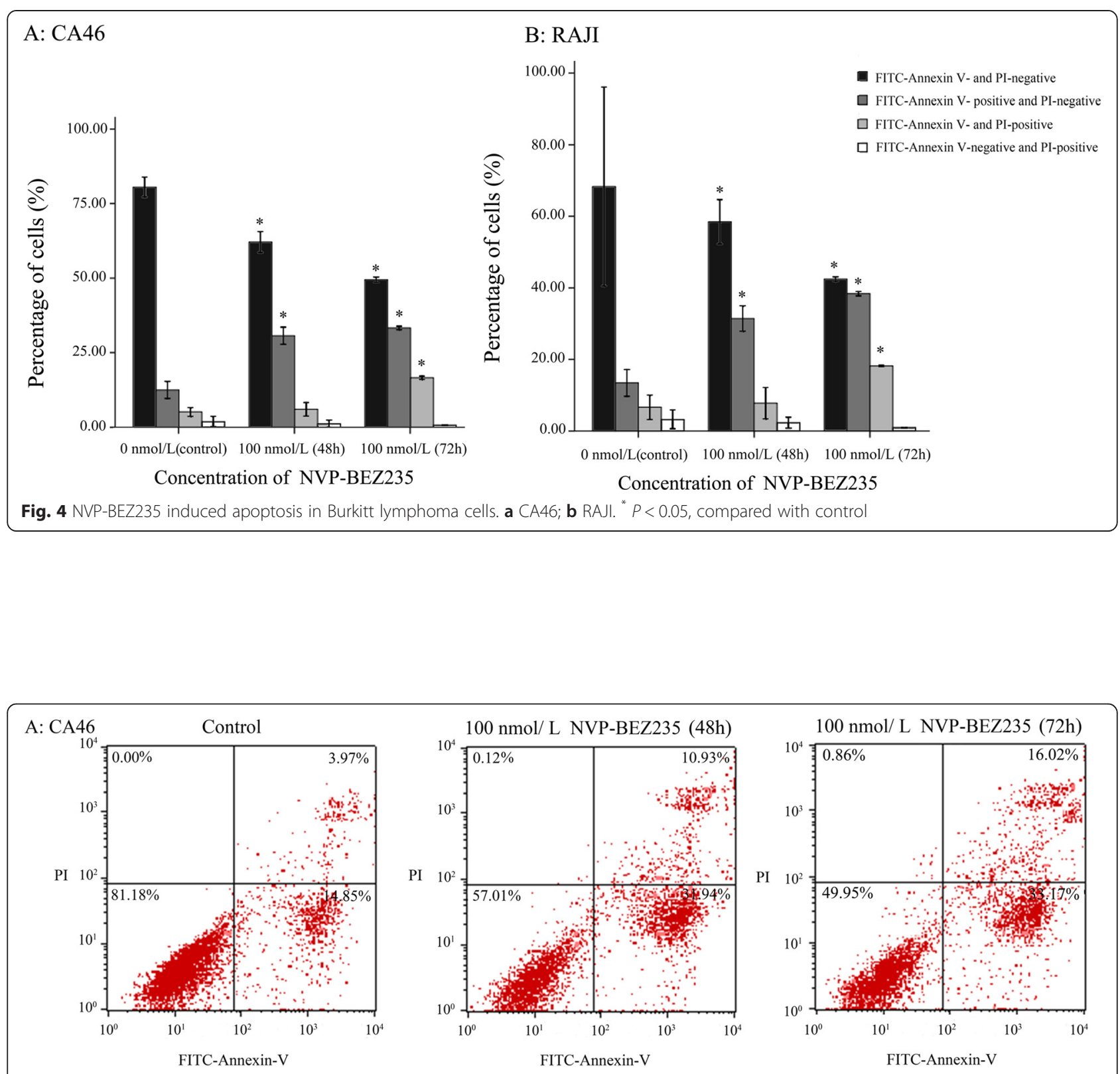

B: RAJI

$100 \mathrm{nmol} / \mathrm{L}$ NVP-BEZ235 (48h)
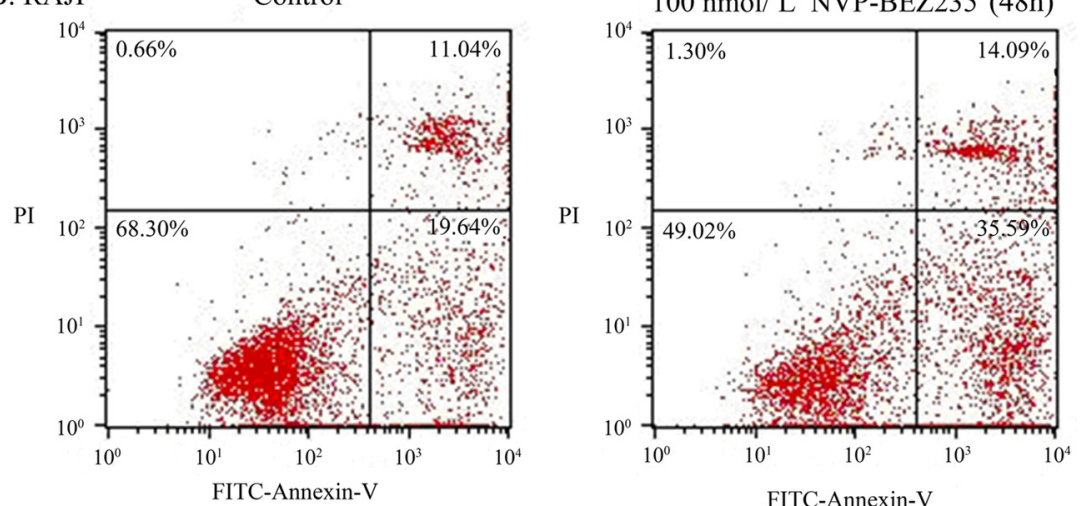

$100 \mathrm{nmol} / \mathrm{L}$ NVP-BEZ235 (72h)

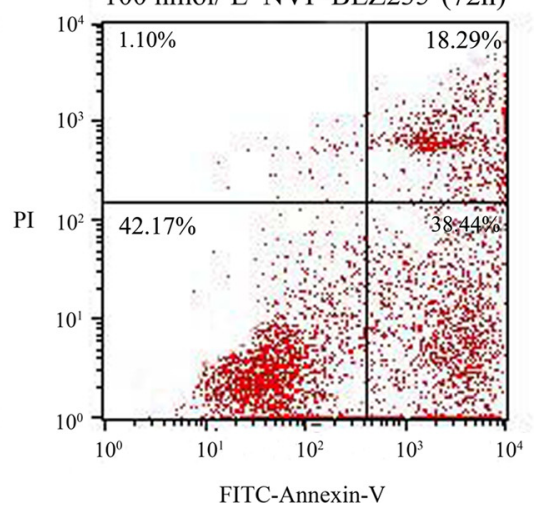

Fig. 5 Apoptosis was detected by flow cytometry using Annexin- $V$ and propidium iodide staining methods 
$\mathrm{L}$ of NVP-BEZ23 for $48 \mathrm{~h}$ and $72 \mathrm{~h}(\mathrm{P}<0.05)$. Moreover, although $48 \mathrm{~h}$ treatment by $100 \mathrm{nmol} / \mathrm{L}$ of NVP-BEZ235 did not cause the significant increase of late apoptotic cells (FITC Annexin V and PI positive) $(\mathrm{P}>0.05)$, the late apoptotic cells were significantly increased after $72 \mathrm{~h}$ incubation of $100 \mathrm{nmol} / \mathrm{L}$ of NVP-BEZ235 $(P<0.05$, Figs. 4 and 5).

\section{Effect of NVP-BEZ235 on PI3K/AKT/mTOR pathway in BL cells}

Figures 6 and 7 showed the western blotting results. The phosphorylation levels of AKT (Thr308), AKT (Ser473), and PRS6 were modestly inhibited by NVP-BEZ235 in both CA46 and RAJI cells $(P<0.05)$. Moreover, the inhibition effect was significantly enhanced with the increasing dose of NVP-BEZ235, indicating this inhibition effect was dose-dependent $(P<0.05$, Fig. $6 \mathrm{~b})$. In addition, the phosphorylation levels of AKT (Ser473) and PRS6 were also modestly decreased after the cells were incubated with $100 \mathrm{nmol} / \mathrm{L}$ of NVP-BEZ235 for 3, 6, 12, 24, and $48 \mathrm{~h}$. Meanwhile, NVP-BEZ235 also modestly inhibited the phosphorylation of AKT (Thr308) with the incubation time of $3,6,12 \mathrm{~h}(P<0.05)$. However, the phosphorylation level of AKT (Thr308) recovered to baseline after the cells were treated by $100 \mathrm{nmol} / \mathrm{L}$ of NVP-BEZ235 for 24 and $48 \mathrm{~h}(P>0.05)$. Results indicated that there was no obvious time-dependent inhibition effect of NVP-BEZ235 on the phosphorylation of AKT (Thr308), AKT (Ser473), and PRS6 (Fig. 7b).

\section{Discussion}

New therapeutic strategies are necessary for BL, because of the resistance of chemotherapy and poor outcomes. The PI3K/Akt/mTOR pathway is a therapy target of cancer. In this study, we found that the NVP-BEZ235 (a dual inhibitor of PI3K and mTOR) effectively

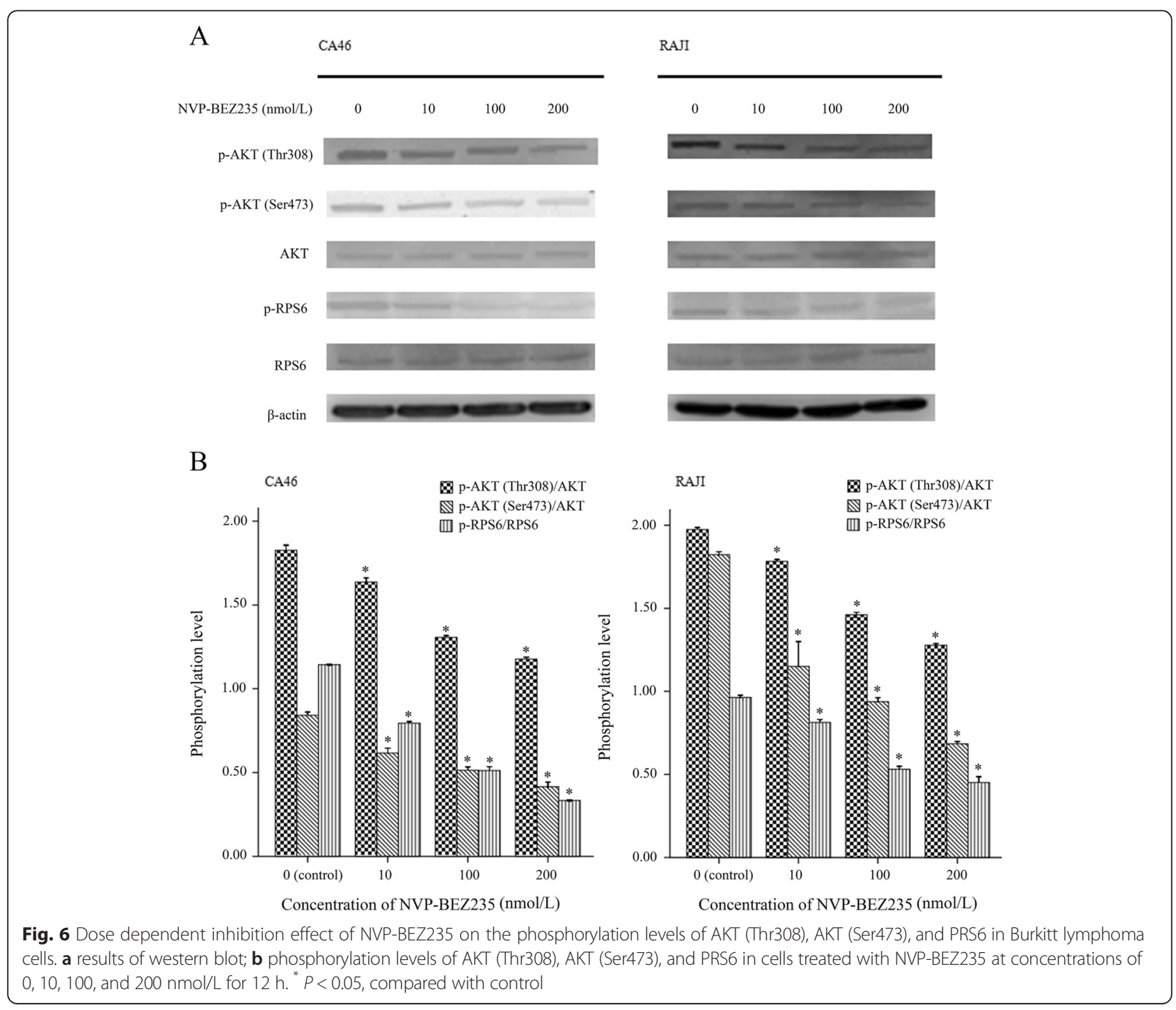



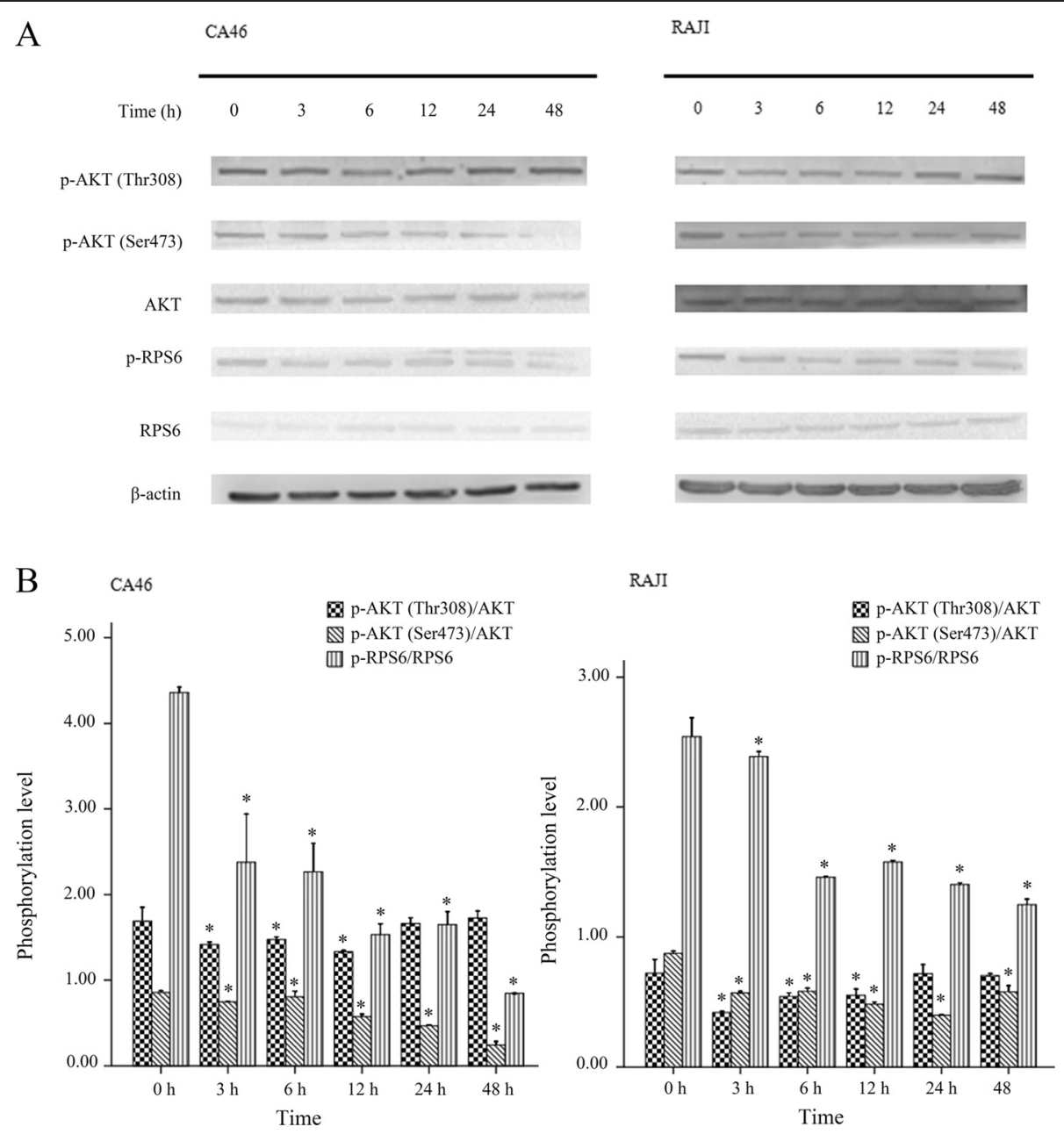

Fig. 7 Phosphorylation levels of AKT (Thr308), AKT (Ser473), and PRS6 were significantly changed in the cells treated with 100 nmol/L NVP-BEZ235 for $0 \mathrm{~h}, 3 \mathrm{~h}, 6 \mathrm{~h}, 12 \mathrm{~h}, 24 \mathrm{~h}$, and $48 \mathrm{~h}$. a results of western blot; b phosphorylation levels of AKT (Thr308), AKT (Ser473), and PRS6 in cells treated with $100 \mathrm{nmol} / \mathrm{L}$ NVP-BEZ235 for $0 \mathrm{~h}, 3 \mathrm{~h}, 6 \mathrm{~h}, 12 \mathrm{~h}, 24 \mathrm{~h}$, and $48 \mathrm{~h} .{ }^{*} \mathrm{P}<0.05$, compared with control

inhibited cell proliferation and prompted cell apoptosis in two BL cell lines. Also, the cells were mostly arrested in G1/G0 phase by NVP-BEZ235 in BL cells. Moreover, the inhibition effect of NVP-BEZ235 on cell proliferation was time and dose-dependent. In addition, the phosphorylation levels of AKT (Thr308), AKT (Ser473), and PRS6 were also modestly changed by NVP-BEZ235. The dose-dependent inhibition effect of NVP-BEZ235 was also found on phosphorylation of AKT (Thr308), AKT (Ser473), and PRS6. However, this inhibition effect was not time-dependent.

Similar with other cancers (such as endometrial carcinomas [25], human pancreatic cancer [26], thyroid cancer [27] and osteosarcoma [28]), NVP-BEZ235 also suppresses cell proliferation by inducing G0/G1 cell-cycle arrest in BL cells. Meanwhile, significantly decreased phosphorylation of AKT (Thr308), AKT (Ser473), and PRS6 in BL cells treated by NVP-BEZ235, indicated that the PI3K/Akt/mTOR pathway was deregulated by NVPBEZ235 in BL cells. It was reported that BL cells (P493-6) could be arrested in G0/G1 after the expression of myc was switched off, which was associated with the inhibition of a set of cell cycle activators (cyclin D2, cyclin E and Cdk4) [29]. Moreover, the expression of Cyclin D was found to be associated with activation of Akt, which was depended on the phosphorylation of AKT (Thr308) and AKT (Ser473), in PI3K/Akt/mTOR pathway [30]. In addition, it was reported that the PI3K/Akt/mTOR pathway involved Akt-mediated phosphorylation of FoxO transcription factors, which was required by the Mycinduced proliferation and transformation [31]. Meanwhile, down-regulation of Cyclin D involves the cell cycle arrest induced by FoxO Transcription Factors [32]. Therefore, the G0/G1 cell-cycle arrest induced by NVP-BEZ235 in this study might be caused by the inhibition of PI3K/Akt/ mTOR pathway, which could suppress Myc-induced 
proliferation by decreasing the expression of Cyclin D and phosphorylation of FoxO transcription factors. Besides, the dose-dependent effect demonstrated that high dose of NVP-BEZ235 could significantly inhibit the PI3K/Akt/ mTOR pathway than low dose of NVP-BEZ235. The most appropriate application dose of NVP-BEZ235 need to be further investigated.

In this study, apoptosis of BL cells was also induced by NVP-BEZ235. Considering the mutant of p53 in the two cell lines (CA46 and RAJI), the independently of p53 in the NVP-BEZ235 induced apoptosis of BL cells was confirmed, which was in line with the results of Shortt et al. [23]. However, the mechanism for NVPBEZ235 induced apoptosis of BL cells still need more studies to explore. Previous studies have reported that the S6 kinase (S6K) play roles in different mechanisms of apoptosis [33-35]. In PI3K/Akt/mTOR pathway, activation of mTOR results in the phosphorylation of numerous substrates, including the phosphorylations of S6 kinase (S6K) by mTORC1 [36]. Then the PRS6, as the substrate of S6K, would be phosphorylated [37]. Moreover, it was reported that the PRS6 was also significantly associated with apoptosis (such as gamma irradiationinduced apoptosis, and cisplatin-induced apoptosis) [38, 39]. Thus, we speculated that the effect of NVP-BEZ235 on apoptosis of BL cells may be associated with the phosphorylation of PRS6 and SK6 may play important roles in this effect.

However, some limitation should be noted in this study. Firstly, we have found the inhibition effect of NVP-BEZ235 on PI3K/Akt/mTOR pathway which was associated with chemoresistance of BL cells [18]. Nevertheless, we have not concerned on the changes of chemoresistance by NVP-BEZ235 in BL cells. Further studies were required to investigate it for further exploring the clinical value of NVP-BEZ235. Secondly, the time dependent effect of NVP-BEZ235 on inhibiting cell proliferation was significant, but there was no obvious time-dependent inhibition effect of NVP-BEZ235 on the phosphorylation of AKT (Thr308), AKT (Ser473), and PRS6. Especially for the phosphorylation level of AKT (Thr308), it recovered to baseline after the cells were treated by NVP-BEZ235 for $24 \mathrm{~h}$ and $48 \mathrm{~h}$. Hence, the time-dependent effect of NVP-BEZ235 on BL cells demands more investigations and evidences. In addition, because the FACS staining was just used for assessing the effect of NVP-BEZ235 on cell cycle in this study, so the FACS staining after incubating cells with the drug for $72 \mathrm{~h}$ was not performed to verify the effect of NVP-BEZ235 on apoptosis. Although NVP-BEZ235 induced apoptosis of BL cells were found by the Annexin V and PI staining after $72 \mathrm{~h}$ treatment by $100 \mathrm{nmol} / \mathrm{L}$ of NVP-BEZ235, further studies were required to confirm the results of this study.

\section{Conclusions}

In conclusion, NVP-BEZ235 might effectively inhibit BL cells proliferation by G0/G1 cell-cycle arrest through deregulating the PI3K/Akt/mTOR pathway, which was associated with the suppression of Myc-induced proliferation. Moreover, the BL cells apoptosis may be induced by NVPBEZ235 through decreasing the phosphorylation of PRS6. This study further confirmed the effect of NVP-BEZ235 on BL cells and provided evidence for the clinical application of NVP-BEZ235 on the treatment of BL.

\section{Abbreviations \\ BL: Burkitt lymphoma; GC: Germinal center; MTT: Manganese tricarbonyl transfer; PBS: Phosphate-buffered saline; PI3K/Akt/mTOR: Phosphatidylinositol 3-kinase/Akt/mammalian target of rapamycin; SDS: Sodium dodecyl sulfate-polyacrylamide.}

\section{Competing interests}

The authors declare that they have no competing interests.

\section{Authors' contributions}

$\mathrm{CL}$ participated in the design of this study. PX performed the statistical analysis. HX carried out the study, together with $Y Z$, and collected important background information. XZ drafted the manuscript. YH conceived of this study, and participated in the design and helped to draft the manuscript. All authors read and approved the final manuscript.

\section{Acknowledgements}

This work was supported by the Medical Innovation Program of Fujian Province (No. 2014-CX-34) and the Natural Science Foundation of Fujian Province of China (No.2015 J01511).

Received: 7 April 2015 Accepted: 3 June 2015

Published online: 24 June 2015

\section{References}

1. Leoncini L, Stein H. Definition of Burkitt Lymphoma. In: Burkitt's Lymphoma. New York: Springer; 2013. p. 81-93.

2. Perkins AS, Friedberg JW. Burkitt lymphoma in adults. ASH Education Program Book. 2008;2008:341-8.

3. Sekiguchi N, Nishimoto J, Tanosaki R, Kubota N, Yokota Y, Kobayashi Y, et al. EBV-positive Burkitt lymphoma as a late-onset posttransplantion lymphoproliferative disorder after allogeneic stem cell transplantation. Int J Hematol. 2004;79:387-9.

4. Molyneux EM, Rochford R, Griffin B, Newton R, Jackson G, Menon G, et al. Burkitt's lymphoma. Lancet. 2012;379:1234-44.

5. Mutalima N, Molyneux E, Jaffe H, Kamiza S, Borgstein E, Mkandawire N, et al. Associations between Burkitt lymphoma among children in Malawi and infection with HIV, EBV and malaria: results from a case-control study. PloS ONE. 2008;3, e2505.

6. Cairo MS, Gerrard M, Sposto R, Auperin A, Pinkerton CR, Michon J, et al. Results of a randomized international study of high-risk central nervous system B non-Hodgkin lymphoma and B acute lymphoblastic leukemia in children and adolescents. Blood. 2007;109:2736-43.

7. Mbulaiteye SM, Anderson WF, Ferlay J, Bhatia K, Chang C, Rosenberg PS, et al. Pediatric, elderly, and emerging adult-onset peaks in Burkitt's lymphoma incidence diagnosed in four continents, excluding Africa. Am J Hematol. 2012:87:573-8.

8. Aka P, Kawira E, Masalu N, Emmanuel B, Brubaker G, Magatti J, et al. Incidence and trends in Burkitt lymphoma in northern Tanzania from 2000 to 2009. Pediatr Blood Cancer. 2012;59:1234-8.

9. Mbulaiteye SM, Clarke CA, Morton LM, Gibson TM, Pawlish K, Weisenburger DD, et al. Burkitt lymphoma risk in US solid organ transplant recipients. Am J Hematol. 2013;88:245-50.

10. Richter-Larrea JA, Robles EF, Fresquet V, Beltran E, Rullan AJ, Agirre X, et al. Reversion of epigenetically mediated BIM silencing overcomes chemoresistance in Burkitt lymphoma. Blood. 2010;116:2531-42. 
11. Sander S, Rajewsky K. Burkitt lymphomagenesis linked to MYC plus PI3K in germinal center B cells. Oncotarget. 2012;3:1066-7.

12. Sharp ZD, Bartke A. Evidence for down-regulation of phosphoinositide 3-kinase/Akt/mammalian target of rapamycin (PI3K/Akt/mTOR)-dependent translation regulatory signaling pathways in Ames dwarf mice. J Gerontol A Biol Sci Med Sci. 2005;60:293-300

13. Morgensztern D, Mcleod HL. PI3K/Akt/mTOR pathway as a target for cancer therapy. Anticancer Drugs. 2005;16:797-803.

14. Brown RE. Morphoproteomics: exposing protein circuitries in tumors to identify potential therapeutic targets in cancer patients. Expert Rev Proteomics. 2005;2(3):337-48.

15. Yip PY. Phosphatidylinositol 3-kinase-AKT-mammalian target of rapamycin (PI3K-Akt-mTOR) signaling pathway in non-small cell lung cancer. Translational Lung Cancer Research. 2015:4(2):165.

16. Domina AM, Van Doorn C-C. The effects of (-)-epigallocatechin-3-gallate (EGCG) and phosphatidylinositol 3-kinase (PI (3) K) inhibition on Burkitt lymphoma cells. FASEB J. 2013;27:1167.1163.

17. Huang $Y$, Hu J, Zheng J, Li J, Wei T, Zheng Z, et al. Down-regulation of the PI3K A Akt signaling pathway and induction of apoptosis in CA46 Burkitt lymphoma cells by baicalin. J Exp Clin Cancer Res. 2012;31:48.

18. Skomra A, Czuczman NM, Mavis C, Rolland DC, Lim M, Awasthi A, et al. The Acquirement Of Rituximab Resistance Is Associated With De-Regulation Of The PI3K/Akt/mTOR Signaling Pathway Leading To Chemotherapy Resistance In Burkitt Lymphoma Pre-Clinical Models. Blood. 2013;122:5144.

19. Maira S-M, Stauffer F, Brueggen J, Furet P, Schnell C, Fritsch C, et al. Identification and characterization of NVP-BEZ235, a new orally available dual phosphatidylinositol 3-kinase/mammalian target of rapamycin inhibitor with potent in vivo antitumor activity. Mol Cancer Ther. 2008;7:1851-63.

20. Mukherjee B, Tomimatsu N, Amancherla K, Camacho CV, Pichamoorthy N, Burma S. The dual PI3K/mTOR inhibitor NVP-BEZ235 is a potent inhibitor of ATM-and DNA-PKCs-mediated DNA damage responses. Neoplasia. 2012;14:34-IN38.

21. Del Alcazar CRG, Hardebeck MC, Mukherjee B, Tomimatsu N, Gao X, Yan J, et al. Inhibition of DNA double-strand break repair by the dual PI3K/mTOR inhibitor NVP-BEZ235 as a strategy for radiosensitization of glioblastoma. Clin Cancer Res. 2014;20:1235-48.

22. Cerniglia GJ, Karar J, Tyagi S, Christofidou-Solomidou M, Rengan R, Koumenis C, et al. Inhibition of autophagy as a strategy to augment radiosensitization by the dual phosphatidylinositol 3-kinase/mammalian target of rapamycin inhibitor NVP-BEZ235. Mol Pharmacol. 2012;82:1230-40.

23. Shortt J, Martin BP, Newbold A, Hannan KM, Devlin JR, Baker AJ, et al. Combined inhibition of PI3K-related DNA damage response kinases and mTORC1 induces apoptosis in MYC-driven B-cell lymphomas. Blood. 2013;121:2964-74.

24. Baumann P, Mandl-Weber S, Oduncu F, Schmidmaier R. The novel orally bioavailable inhibitor of phosphoinositol-3-kinase and mammalian target of rapamycin, NVP-BEZ235, inhibits growth and proliferation in multiple myeloma. Exp Cell Res. 2009;315:485-97.

25. Shoji K, Oda K, Kashiyama T, Ikeda Y, Nakagawa S, Sone K, et al. Genotype-dependent efficacy of a dual PI3K/mTOR inhibitor, NVP-BEZ235, and an mTOR inhibitor, RAD001, in endometrial carcinomas. PloS ONE. 2012;7, e37431.

26. Venkannagari S, Fiskus W, Peth K, Atadja P, Hidalgo M, Maitra A, et al. Superior efficacy of co-treatment with dual PI3K/mTOR inhibitor NVP-BEZ235 and pan-histone deacetylase inhibitor against human pancreatic cancer. Oncotarget. 2012;3:1416-27.

27. Lin S-F, Huang Y-Y, Lin J-D, Chou T-C, Hsueh C, Wong RJ. Utility of a PI3K/mTOR inhibitor (NVP-BEZ235) for thyroid cancer therapy. PloS ONE. 2012;7, e46726.

28. Gobin B, Battaglia S, Lanel R, Chesneau J, Amiaud J, Rédini F, et al. NVP-BEZ235, a dual PI3K/mTOR inhibitor, inhibits osteosarcoma cell proliferation and tumor development in vivo with an improved survival rate. Cancer Lett. 2014:344:291-8.

29. Pajic A, Spitkovsky D, Christoph B, Kempkes B, Schuhmacher M, Staege MS, et al. Cell cycle activation by c-myc in a Burkitt lymphoma model cell line. Int J Cancer. 2000;87:787-93.

30. Muise-Helmericks RC, Grimes HL, Bellacosa A, Malstrom SE, Tsichlis PN, Rosen N. Cyclin D expression is controlled post-transcriptionally via a phosphatidylinositol 3-kinase/Akt-dependent pathway. J Biol Chem. 1998;273:29864-72.
31. Bouchard C, Marquardt J, Bras A, Medema RH, Eilers M. Myc-induced proliferation and transformation require Akt-mediated phosphorylation of FoxO proteins. EMBO J. 2004;23:2830-40.

32. Schmidt M, De Mattos SF, Van Der Horst A, Klompmaker R, Kops GJL, Lam EW-F, et al. Cell cycle inhibition by FoxO forkhead transcription factors involves downregulation of cyclin D. Mol Cell Biol. 2002;22:7842-52.

33. Wan X, Helman L. Effect of insulin-like growth factor II on protecting myoblast cells against cisplatin-induced apoptosis through p70 S6 kinase pathway. Neoplasia. 2002;4:400-8.

34. Padmanabhan J, Brown KR, Padilla A, Shelanski ML. Functional role of RNA polymerase II and P70 S6 kinase in KCl withdrawal-induced cerebellar granule neuron apoptosis. J Biol Chem. 2015;290(9):5267-79.

35. Dhar R, Persaud SD, Mireles JR, Basu A. Proteolytic Cleavage of p70 Ribosomal S6 Kinase by Caspase-3 during DNA Damage-Induced Apoptosist. Biochemistry. 2009;48:1474-80

36. Sarbassov DD, Guertin DA, Ali SM, Sabatini DM. Phosphorylation and regulation of Akt/PKB by the rictor-mTOR complex. Science. 2005;307:1098-101.

37. Brian M, Bilgen E, Diane CF. Regulation and function of ribosomal protein S6 kinase (S6K) within mTOR signalling networks. Biochem J. 2012;441:1-21.

38. Kim JH, Jeong SJ, Kim B, Yun SM, Choi DY, Kim SH. Melatonin synergistically enhances cisplatin-induced apoptosis via the dephosphorylation of ERK/p90 ribosomal S6 kinase/heat shock protein 27 in SK-OV-3 cells. J Pineal Res. 2012;52:244-52.

39. Neise D, Sohn D, Stefanski A, Goto H, Inagaki M, Wesselborg S, et al. The p90 ribosomal 66 kinase (RSK) inhibitor BI-D1870 prevents gamma irradiation-induced apoptosis and mediates senescence via RSK-and p53-independent accumulation of p21WAF1/CIP1. Cell Death Dis. 2013;4:e859.

\section{Submit your next manuscript to BioMed Central and take full advantage of:}

- Convenient online submission

- Thorough peer review

- No space constraints or color figure charges

- Immediate publication on acceptance

- Inclusion in PubMed, CAS, Scopus and Google Scholar

- Research which is freely available for redistribution 